Gender and New India

Dr. Geetabjali Srivastava

\title{
Gender and New India
}

\author{
Dr. Geetabjali Srivastava \\ Asst. professor, Faculty of Humanities \\ Shri Ramswaroop Memorial University, Deva Road, lucknow \\ Email: geetsri111@gmail.com
}

\begin{abstract}
Gender is defined as the socially constructed relation between men and women, it should not be determined biologically but actually it is constructed socially. They vary among different societies and cultures, classes, ages and during different periods in history. Gender-specific roles and responsibilities are often conditioned by household structure, access to resources, specific impacts of the global economy, and other locally relevant factors such as ecological conditions. Gender relations defines rights, responsibilities, and the identities of men and women in relation to one another.

In Indian context the detrimental cultural practices before marriage like -preference to the boys in education, succession, authority, liberty expression, access to resources and positive attitude. After marriage husbands over-dominance, dominance of In-laws, limitations in continuing relationships with her family members and girl or boy friendship after marriage, social identity, violence through dominance, male dominance over performance of rituals and continuation of lineage in the name of male member of the family contribute to the inequality. In Governance this inequality is visible, after over sixty years of independence women are still exploited, the $73 \mathrm{rd}$ and 74 th constitutional amendments have provided $33 \%$ reservation through Panchayati Raj System in both rural panclhayats and urban local bodies, which is a fabricated empowerment of women and practically it is governed and controlled by husbands of selected women representatives. In Parliament only o6.6-8.4\% representation of women out of 790 seats reflects a huge gender gap in parliamentary and democratic process. Men domination in most of the administrative practices is still existent in India. Therefore the concept of gender in new India is more skewed towards inequality between men and women.
\end{abstract}

Key words:Socially constructed concept, Gender roles, behaviour, relation, inequality

Reference to this paper should be made as follows:

Received: 23.12.2019

Approved: 05.03.2020

Dr. Geetabjali

Srivastava,

Gender and New India

Article No. 04

RJPSS March 2020,

Vol. XLV No. 1, pp. $022-038$

Online available at: https://anubooks.com/

?page id $=6389$

https://doi.org/10.31995/

rjpss.2020.v45i01.004 
RJPSS March 2020 Vol. XLV No.1, ISSN: (P)0258-1701 (e)2454-3403 Impact Factor: 7.712

\section{Introduction}

The concept of gender was first developed by Iill Matthews in 1984 in her study of the construction of femininity. According to Mathews, the concept of gender gives recognition to the fact that every known society distinguishes between women and men. Therefore the concept of gender is a systematic way of understanding men and women socially and the patterning of relationships between them. Gender has been defined as: "The commonly shared expectations and norms within a society about appropriate male and female behaviour, characteristics and roles. Gender can be considered a social and cultural construct that differentiates females from males and thus defines the ways in which females and males interact with each other. These roles and expectations are learned and they can change over time as well as vary within and between cultures." (Bravo-Baumann, 2000).

Gender is also defined as'the relations between men and women, both perceptual and material. Gender should not be determined biologically, as a result of sexual characteristics of either women or men, but actually it is constructed socially. It is a central organizing principle of societies, and often governs the processes of production and reproduction, consumption and distribution'. Despite this definition, gender is often misunderstood as being the promotion of women only. However, as we see the given definition, gender issues focus on women and on the relationship between men and women, their roles, access to and control over resources, division of labour, interests and needs. Gender relations affect household security, family well-being, planning, production and many other aspects of life (Bravo-Baumann, 2000).

The term gender is also used to describe the differences in behaviour between men and women which are described as ,masculine and „feminine . Feminist writings focus on this aspect and claim that these differences are not biological but are social constructions of patriarchal society. Ann Oakley in her book, sex, gender and Society written in 1972 explores the term gender. Oakley says that in the Western culture women play the roles of the „housewife and „mother. This is because women are made to play these roles because of their biology. The western culture also beli eves that any effort to change the traditional roles of men and women in the society can cause damage to the social fabric of the society. Oakley concludes that this view regarding the roles of men and women helps to support and maintain the patriarchal society. Simone de Beauvior in her book „The Second Sex says that "one is not born, but rather becomes a woman". She explains thatgender differences in the society make the man superior through his role as the bread winner. It gives 
him a position of power in the society and family. Gender differences are set in hierarchal opposition such that men are superior and women are subordinate.

\section{Gender in Indian Context}

Despite considering the women as source of power, patients, love, affection, counterpart of a man without her not a single activity is considered as complete and a procreator but on the practical grounds the cultural construct of Indian society which reinforces gender bias against men and women in form of suppression, neglect, torture, exploitation, misbehave with varying degrees and variable contexts against the opposite sex. It has also led to the continuation of India's strong preference for male children. Female infanticide and sex-selective abortion is adopted and strongly reflects the low status of Indian women. Census 2011 shows decline of girl population (as a percentage to total population) under the age of seven, with activists estimating that eight million female foetuses may have been aborted in the past decade. The 2005 census shows infant mortality figures for females and males are 61 and 56, respectively, out of 1000 live births with females more likely to be aborted than males due to biased attitudes.

\section{Gender inequality in India}

Gender inequality in India refers to health, education, economic and political inequalities between men and women in India. Its social causes, impact India's sex ratio, women's health over their lifetimes, their educational attainment, and economic conditions. Gender inequality in India is a multifaceted issue that concerns men and women alike. Some argue that some gender equality measures, place men at a disadvantage. However, when India's population is examined as a whole, women are at a disadvantage in several important ways.

A decline in the child sex ratio (0-6 years) was observed with India's 2011 census reporting that it stands at 914 females against 1,000 males, dropping from 927 in 2001 - the lowest since India's independence. In some areas the gender ratio found positive in India but again backed by gender discrimination. Increasing the number of female members just have a son e.g six daughters for a single son.The demand for sons among wealthy parents is being satisfied by the medical community through the provision of illegal service of foetal sex-determination and sex-selective abortion. The financial incentive for physicians to undertake this illegal activity seems to be far greater than the penalties associated with breaking the law. Education is not wisely attained by Indian women. Although literacy rates are increasing, female literacy rate lags behind the male literacy rate. A Comparison between Literacy Rate Census of India 2001 and 2011 reveals that literacy for females stands at $65.46 \%$, compared to $82.14 \%$ for males. An underlying factor for such low literacy rates are 
parents' perceptions that education for girls are a waste of resources as their daughters would eventually live with their husbands' families and they will not benefit directly from the education investment.

Gender in Present Indian Scenario reflects the reality of gender inequality in India is very complex and diversified, because it is present in many ways, many fields and many classes and fields like education, employment opportunities, where men are always preferred over women. The gender inequality faced by women was so much that many women claimed may God give sons to all. This is a fact and India has witnessed gender inequality from its early history due to its socio-economic and religious practices that resulted in a wide gap between the position of men and women in the society. Clearly, then gender gaps that are widespread in access to basic rights, access to and control of resources, in economic opportunities and also in power and political voice are an impediment to development. Consider the case - a girl taking admission in mechanical engineering which always becomes a subject matter of criticism because engineering services comes under male domain and preferred by society.

Despite the legislation like Pre Conception and Pre natal Diagnostic Test Act1994 in India, a sex-selection phenomenon has been in place since the 1980s, with men born during this period now at marriageable age. Then the urbanization since the 1990s where a lot of families and men have moved to cities to look for work. People are much wealthier but at the same time there's pressure to produce sons as an heir, so educated, wealthy families are now more likely to have sex selection. All these factors are coming to play and creating this toxic mixture, which has turned violence against women into a bigger issue today

After the development of science and technology, female foeticide is being practiced on a large scale. This has led to a drop in the female ratio. According to the census 2001, the sex ratio in India is 927 females to 1,000 males. And then dowry have become common and started female infanticide practices in few areas. In many parts of India, women are viewed as an economic liability despite contribution in several ways to our society and economy. The crime graph against women is increasing at an alarming rate. The condition of an Indian widow is quite deplorable. At home, the woman's contribution towards home as a housewife is not recognized. Domestic Violence, Rape, Sexual Exploitation, molestation, eve-teasing, forced prostitution, sexual harassment at work places etc is a common affair today and in some cases. It's too tragic that it gets the global attention as cruel The major reasons for this inequality are identified as the need of a male heir for the family, huge dowry, continued financial support to girl child, poverty, domestic violence, farming as major 
job for poor and the caste system.

India ranks 132 out of 187 countries on the gender inequality index - lower than Pakistan (123), according to the United Nations Development Program's Human Development Report 2013. The report said all countries in South Asia, with the exception of Afghanistan, were a better place for women than India, with Sri Lanka (75) topping them all. Nepal ranked 102nd and Bangladesh 111th.

Gender inequality is especially tragic not only because it excludes women from basic social opportunities, but also because it gravely imperils the life prospects of future generations. Indian families often prefer boys to girls, and female feticide is tragically common. Only 29\% of Indian women above the age of 15 in 2011 were a part of the country's labor force, compared to $80.7 \%$ men. In Parliament, only $10.9 \%$ of lawmakers are women, while in Pakistan $21.1 \%$ are women. In United States which ranks 42 nd on the list, $57.5 \%$ women and $70.1 \%$ men are a part of the labor force. China fared even better, landing 35th. Only $26.6 \%$ women above 25 years received a secondary education in 2010, compared to $50.4 \%$ of men. Pakistan scored even lower, with $18.3 \%$ of women having received secondary education compared to $43.1 \%$ of men. In the U.S., $94.7 \%$ women have received a secondary education - a figure slightly higher than for men (94.3\%). In China, this figure was $54.8 \%$ for women and 70.4\% for men. In India, 200 women died for every 100,000 childbirths, says the report.

\section{Facts of Inequality}

At work, this disparity is visible through a different working environment for women, unequal wages, undignified treatment, sexual harassment, higher working hours, engagement in harmful industries, occupational hazards, working roughly twice as many hours as men and a nearly 27 percentage of women are accounted by unpaid activities. Violence against women is also prominent in India which leads to every 42 minutes a sexual harassment occurring, every 43 minutes a woman kidnapped and every 93 minutes a woman is burnt for dowry. And by the pre quarter of reported, rapes involve girls under the age of 16 years. Every 26 minutes a woman is molested and every 34 minutes a rape take place. Poor health care is another attitude towards women which makes them neglected during illness, recognition of illness by herself, health services as a last resort and reluctance to be examined by male doctors. Lack of education in women has lead to poor literacy leading to gender gap in literacy rate and no higher education. Economic constraints are also imposed to women in India by keeping them as dependents, no equal property rights (as against law), loans of men is paid back by women, economic uncertainty and denial in inheritance of 
properties to orphaned / deserted. Discriminative socialization process is another aspect of inequality towards women which leads to customar practices, more involvement in household activities only (boys not allowed), restricted to play, isolation, separation in schools and public places and restrictions to move freely.

\section{Gender statistics}

The following table compares the population wide data for the two genders on various inequality statistical measures, according to The World Bank's Gender Statistics database for 2012.

\section{Gender Statistic Measure}

Account at a formal financial institution, ( $\%$ of each gender, age $15+)$

Cause of death, by non-communicable diseases, ages 15-34, (\%)

Deposits in a typical month, (\%with an account, age $15+)$

Employees in agriculture, (\% of total labour)

Employees in industry, $(\%$ of total labour $)$

Expected years of schooling

Infant mortality rate, (per 1,000 live births)

Life expectancy at age 60 , (years)

Life expectancy at birth, (years)

Loan from a financial institution in the past year, $(\%$ age $15+)$

Lower secondary school completion rate, $(\%)$

Outstanding loan from banks for heal th or emergencies, $(\%$ age $15+)$

$\begin{array}{cl}\text { F(India) } & \text { M(India) } \\ 26.5 & 43.7 \\ 32.3 & 33.0 \\ 11.2 & 13.4 \\ 59.8 & 43 \\ 20.7 & 26 \\ 11.3 & 11.8 \\ 44.3 & 43.5 \\ 18.0 & 15.9 \\ 68 & 64.5 \\ 6.7 & 8.6 \\ 76.0 & 77.9 \\ 12.6 & 15.7 \\ 2.26 & 2.35 \\ 96.6 & 96.3 \\ 0.98 & 1.0 \\ 41.1 & 58.9 \\ 46 & 54 \\ 85.5 & 80.6 \\ 4 & 3.1 \\ 10.6 & 9.4 \\ 18.6 & 12.7\end{array}$

Outstanding loan from banks to purchase a home, $(\%$ age $15+)$

Primary school completion rate, $(\%)$

Ratio to males in primary and secondary education (\%)

Secondary school education, gender of teachers $(\%)$

Secondary school education, pupils (\%)

Self-employed, ( $\%$ employed)

Unemployment, (\% of labour force, ILO method)

Unemployment, youth ( $\%$ of labour forœ ages 15-24, ILO method)

Withdrawals in a typical month, (\% with an account, age $15+)$

\section{(F-Female, M-Male, NA-Not Available)}

The table reveals that the gender inequality is existent in socio-economic aspect of male and female at Pan Indic level. It could be analysed under following categories.

\section{Economic self-dependency}

The table shows that economic and educational backwardness are the root cause of underprivileged condition of women and promoting gender inequality nationwide. Another point is remarkable that in India, the percentage of women is higher in low paid sector of economy such as agriculture (Female -59.8\% and Male$43 \%$ ) as well as the percentage of women is lower in high paid sector, such as 
industry (Female $-20.7 \%$, Male- $26 \%$ ). The given situation reflects the unfair economic practices towards women in India. The table also shows a highly dissatisfactory condition of access of bank accounts by women at national (Female - 26.5\%, Male43.7\%) This is a reflection of financial dependency of women upon men which leads toward exploitative practices against women .Apart from this the economic dependencybecomes the biggest hurdle in the way to achieve a self-dependent empowered status of women. If we throw light on the deposit and withdrawal practices of women in India, we will see that the withdrawals (Female - $18.6 \%$, Male $-12.7 \%$ ) are higher than the deposits (Female - $11.2 \%$, Male- $13.4 \%$ )as compared to men. It shows an adverse relation of financial securityand empowerment of men and women in India.

\section{Education}

The table also reveals the educational gap between men and women in India. Although the women are behind men in this field but the condition is little better than the financial self-dependency of women. Due to intensive educational programmes (eg. Sarva Shiksha Abiyan/Education for All Campaign ,Beti bachao Beti Padhao/Save Girl Child ,Educate Girl Child, Kasturba Gandhi BalikaVidayalaya etc.), the gap between Primary school completion rate (Female - 96.6\%, Male $96.3 \%$ ) is not so vast and women are in little better condition. But as the education level increases, the gap becomes wider between the ratio of Male and Female education. We can find an increasing tendency between the ratio of Lower secondary school completion rate of male and female in India (Female - 76.0\%, Male $-77.9 \%$ ). In the same manner the gap between the primary and secondary education of male and female becomes wider in India (Female -0.98, Male -1.0). The gap significantly expands as we reach up to secondary education (Female $-46 \%$, Male - 54\%). The above mention condition shows the biased and neglected attitude of Indian society towards the female education.A number of social factors responsible for this tendency in India such as Dowry, Poverty ,Ritual of Kanyadaan, Ideology of Paraaya Dhan(property of other or to whom she will be married), Unemployment, Misbehaviour with female in social life, orthodox mentality and exploitation of women promote the restriction over female education. Although there is a gap between the education level of male and female but there is no huge difference in expected years of schooling of both the gender (Female- 11.3, Male\% - 11.8\%)

\section{Health}

The table reveals that the condition of health of women is satisfactory except infant mortality rate (Female-44.3\%, Male- $43.5 \%$ ), The level of life expectancy at birth and at the age of 60 ,and percentage of death caused by non-communicable 
diseases, between the age group of 15-34 years, is favourable than men .Increasing level of awareness through intensive information dissemination about causative factors and preventive measures of different diseases contributed the satisfactory health condition of women in India. The root cause of infant mortality is poverty especially in

\section{Employment}

The table shows that the youth (labour force ages 15-24 years) unemployment rate of female is higher than male in India (Female- 10.6, Male - 9.4) and overall unemployment rate is(Female $-4 \%$, Male $-3.1 \%$ ) is also not favourable in our country .The situation reflects that female self-dependency is a less prioritized feature of Indian social life. There are various socio-cultural and economic factors which are directly and indirectly responsible for this situation such as -low level of education, poverty ,Patriarchy and male dominance ,patrilocal marriage system and orthodox attitude of society towards women. The condition of women is favourable only in the area of self-employment (Female -85.5\%, Male - 80.6\%)

\section{Prevailing factors responsible for gender inequality in new India}

\section{Patrilocality}

Many cultures practice patrilocality whereby a married couple lives near or with the husband's parents. When a woman gets married, she essentially ceases to be a member of her birth family and joins her husband's family. Under this system, parents potentially reap more of the returns to investments in a son's health and education because he will remain a part of their family, whereas a daughter will physically and financially leave the house after marriage. Co-residence of adult sons and elderly parents is much more common in Asia, the Middle East, and North Africa than in Europe, sub-Saharan Africa, and the Americas.

Within India, the northern region has a much stronger patrilocal and patrilineal system than the south, which is one explanation for why gender inequality is more pronounced in the north (Dyson and Moore, 1983). For example, Chakraborty and Kim (2010) examine the 1901 Indian Census and find that the sex ratio was less male-skewed in the south, a pattern that continues to hold today. More generally, Ebenstein (2014) shows that the male to-female sex ratio is positively correlated with the rate of co-residence between adult sons and their parents both across and within countries.

If parents fully internalized their daughters' returns to nutrition, health care, and schooling, then patrilocality would not necessarily cause gender gaps in these inputs. In practice, though, the longer duration that parents will co-reside and pool 
financial resources with their sons seems to cause them to invest disproportionately in sons. For example, parents are more likely to seek medical care for a sick son than sick daughter. In one study, 405 parents in India who had been advised that their child needed surgery to correct a congenital heart condition were followed up one year later; 70 percent of the boys but only 44 percent of the girls had undergone surgery (Ramakrishnan et al., 2011). The financial mindset about investing in daughters is encapsulated in an often quoted Indian saying that "raising a daughter is like watering your neighbours' garden." This sentiment is echoed in a Chinese proverb that describes raising a daughter as "ploughing someone else's field."This attitude leads to the discriminatory practices in upbringing and development of a girl chid which results in exploitation, suppression, ignorance, neglect and torture in every walk of life .

\section{Poverty}

Poverty could exacerbate the tendency to invest more in sons than daughters. Suppose the net returns to surgery are positive for both boys and girls but higher for boys. If a family is liquidity-constrained, they might seek medical care only for their son, but with more available resources, they would seek care for both their son and daughter. (The same reasoning could apply if parents invest more in boys because boys have higher labor market returns to health, and not just when the gender gap is due to cultural practices.) Consistent with the idea that poverty can widen the gender gap in investment, Rose (1999) found that favourable rainfall in rural India increased girls' survival more than boys'. Theoretically, parents' marginal spending need not always benefit the disadvantaged group, however (Kanbur and Haddad, 1994). Oster (2009) reports that better access to health care initially widens the gender gap in vaccinations in India, but further improvements close the gender gap.

\section{Old-age support from sons}

Closely linked to patrilocality is the fact that sons traditionally provide oldage support for their parents in societies such as China and India. For example. When the Chinese government instituted the Rural Old-Age Pension Program, parents now had a better substitute for old-age support from sons, and thus their desire to have a son should have abated. Households without sons are more likely to participate in the pension program (and also to have more savings). In addition, having access to the pension program is associated with a less skewed sex ratio. Here one again sees how culture and development interact. With the rollout of the pension, the cultural norm that sons not daughters support parents did not change, but its implications for the desire to have a son and the skewed sex ratio did change. When a formal institution

for retirement savings arose, the informal method of relying on sons became less 
important, and therefore this force driving son preference became less relevant. Hence gender discrimination is supported by financial condition of the family as well as the cultural practices in country.

\section{Dowry system}

Another accelerator for gender discrimination in India. It is generally considered as a return to be received from the family of Bride for the expenses incurred on education and settlement of the Bridegroom. Because it becomes the responsibility of the bridegroom to bear all the expenses to be incurred on different needs of the bride for lifelong .Dowry is a payment that a bride's parents make to the couple at the time of marriage. According to Boserup (1970), dowry systems emerged mainly in societies where women played a lesser role in agriculture. Dowry has disappeared in many societies, notably in Europe, but it has persisted in, for example, South Asia. In fact, over the past several decades, the prevalence of dowry has increased in Bangladesh, and the real value of dowry payments has risen considerably in India (Rao, 1993; Anderson, 2007). In addition, the property rights to dowry as practiced today differ from those seen historically in Europe. In ancient Rome and medieval Western Europe, the bride held the rights to the dowry; it was her pre-mortem inheritance from her parents (Anderson, 2007). In this formulation, the dowry system was intended to improve the financial well-being of females. However, in societies where dowry is used today, the groom typically controls the money - dowry is the price of a groom. Dowry is thus a financial cost to parents of having daughters.

\section{Patrilineality}

In a patrilineal system, names and property pass to the next generation through male descendants. This system puts sons on a higher footing than daughters, and the specific feature of land inheritance is especially likely to have effects on gender gaps. For example, in India because widows traditionally do not inherit their husbands' ancestral property, they rely on their sons as their conduit for holding onto the family property and maintaining their standard of living in widowhood. This consideration might be one reason that the desire to have sons is often not appreciably different between women and men. Under the Hindu Succession Act of 1956, sons shared the right to inherit ancestral property in India. In the 1980s and 1990s, the law was amended in four states to make daughters' status equal to sons'. The reforms had some bite: In the sample that Deininger (2013) analyze, 8 percent of daughters whose fathers died before the reforms inherited land; the proportion increased to 16 percent among those whose father died after the reforms. (About70 percent of fathers owned 
land; the fraction of sons who inherited land remained steady at 70 percent before and after the reforms.) As a result of the law changes, women's age of marriage rose, consistent with their more bargaining power within the family and financial independence (Deininger et al., 2013). The reforms also increased girls' schooling, presumably because their mothers were more empowered in the household or because education and asset ownership are complements (Deininger et al., 2013; Roy, 2013). However, the legal reforms also seem to have had some negative consequences for women. Anderson and Genicot (2014) find that they led to a rise in suicides, which they conjecture is due to a backlash effect whereby the increase in female bargaining power sparked marital conflict. Hence financial empowerment can control the gender inequality to some extent but not completely.

\section{Role of sons in religious rituals}

In certain belief systems, such as Confucianism in China and Hinduism in India, sons play a special role. Confucianism encourages the patrilineal and patrilocal system in China, Vietnam, and elsewhere. But another part of the special role of sons is in rituals. Ancestor worship within Confucianism involves rituals where a son plays an essential part. Similarly, son preference is mentioned in the Vedas, the ancient Hindu texts. In addition, in Hindu societies, it is supposed to be a son who lights a deceased person's funeral pyreand brings him or her salvation. Hindu kinship norms are adhered to more strictly amongupper castes than lower castes (Mandelbaum, 1970), and Chakraborty and Kim (2010), in their analysis of the 1901 Indian Census, find a more skewed sex ratio for upper castes than lower castes. The funeral-pyre underpinning of son preference specially generates a strong desire for one son (with further sons perhaps serving as insurance in case the first son predeceases his parents). Other reasons for son preference such as wanting someone to carry on the family name or widows wanting to retain family land also make the first son especially valuable. Consistent with this idea, Jaya chandran (2014) finds that parents in India strongly want to have one son and, once they have one son, prefer a balanced gender ratio, more or less. In this way cultural and religious practices are promoting gender inequality in our country.

\section{Desire to protect female safety and purity}

Concern for women's and girls' safety and purity" constrains their physical mobility in many developing countries. It is difficult to say how much of the limited mobility is out of genuine concern for women's welfare, aimed at protecting them from harassment and sexual violence, and how much is simply a way to stifle female autonomy. Restrictions on female mobility often seem largely aimed at keeping 
unmarried women chaste and married women faithful. In any case, they are a proximate cause of reduced female schooling and career opportunities. One reason parents cite for not educating their daughters is the distance to school. One reason parents cite for not educating their daughters is the distance to school.

Muralidharan and Prakash (2013) show that a program that gave girls bicycles to travel to school in India similarly had a sizable impact on girls' school participation. This reflects that better infrastructure, which comes with economic development, could set some of the effect that social constraints on girls' mobility have on their education. Besides distance to school, parents might also want their daughters segregated from male peers or teachers. The construction of girl-friendly" schools which were equipped with sex-segregated latrines also help for improved school attendance and academic achievement. Another consideration is that parents feel pressure to marry off their daughters early in societies where female chastity is prized by men, which leads to early school dropout. One of the tenets of the Hindu caste system is that women should be protected from pollution," which includes men outside their families. Disallowing women from working outside the home is one way of maintaining their purity (Chen, 1995). Because these restrictions apply more stringently to upper caste women in India, lower caste women often have more professional exibility and autonomy. Apart from this women is more considered as a subject matter of pride hence esteem, social image, honour and respects of the family get more attached with women. Lot of incidences in our history are the evidence of political alliance through marriage or exchange of women. For e.g. marriage of Jodha bai and Akbar, marriage of Subhadra,

\section{Distinction between desire for sons and higher investment in sons}

Parents' favouritism toward boys encompasses both wanting to have sons more than daughters and choosing to invest more in sons than daughters due to cultural practices and social acceptance. These two dimensions of favouritism often go hand-in-hand, but they are not identical.

\section{Policy approaches to reduce gender bias}

Eliminating gender inequality might require explicit policy intervention. Moreover, one might not want to wait patiently as the problem of gender inequality resolves itself via economic growth. One type of gender-progressive policy is granting legal rights to women. A powerful example of this tool is India's move to reserve political seats for women. A fraction of seats at various levels of government are, by mandate, held by women. The most direct impact of the law change on women's welfare has been to close the gap in women's representation; female leaders 
implement policies that react in a better way to the policy preferences of their female constituents (Chattopadhyay and Duo, 2004). Moreover, this reform has begun to reshape attitudes toward women as leaders (Beaman et al., 2009) and raised the wit aspirations of and long-term investments in girls (Beaman et al., 2012). To remove gender inequality following measures must be taken:

\section{Strict adherence of legislation}

A limitation of legal reforms is that enforcement is often weak. For example, the legal reform granting women rights to ancestral land in India is not only appropriately practiced but it is far from universally enforced. Similarly, bans on prenatal sex determination, dowry, and child marriage are often minimally enforced and practiced as well as promoted in hidden way. It is also seen that the legal provisions are practiced in the most illegal manner in our India. Hence an implementation and monitoring body must be there for strict adherence of legislation. Apart from this timely hearing and proceeding of the cases is also required to control gender inequality because a long duration of proceeding of the case strengthens the confidence of offenders who committed the crime against women. It can also boot up the morale of victims to come forward for sharing their bitter experience with common people ,just to attain justice and control over repetition of the mishappening with anyone else in the society.

\section{Economic self-dependency}

Second policy tool is financial incentives for parents to invest in or have girls. For example, many states in India offer incentives to have daughters (Anukriti, 2013). Another approach is to shift household financial resources to mothers based on the hypothesis that more influence in the household for women will help break the cycle of gender discrimination because women have less pro-boy bias than men do. There are several pieces of evidence that when women control a larger share of household income, girls' outcomes improve. Apart from this job opportunities must have reservation or expenditure or provision of services or special provisions.

\section{Sensitisation of male members of society}

It's a universal truth that male and female are complimentary to each other. The exploitation and disregard of one adversely affect another one in many ways .In our life there are many situations in which unconditional cooperation of a male to female in form of different relations (father, husband, brother etc.) accelerate the process development of women .Similarly in many situation there is no substitute of unconditional care of women to men in form of different relationships (mother, sister, wife etc.).But there were many socio - economic and political factors (dowry system, 
patriarchy, Patrilineality, succession of property from father to son etc.) because of which the male dominance was rationalised and being practices from generation to generation. Therefore it is essentially required to sensitise male members about the value of a female in their life and to motivate them to promote and practice gender equality. Sensitisation is required in formal and formal sector both. These may be family, politics, economic processes ,cultural practices ,Judiciary and administration.

\section{Change in pattern of upbringing}

Despite of several initiatives and efforts, the gender discrimination is still dominant in India. The reason behind the condition is that it is inherent in our behaviour and has become a pattern of upbringing. Due to which it is blindly followed by generation to generation. It is logically and rationally accepted not only the male members but also by female members of the society. Still in India a mother itself teaches the chapters to follow gender inequality to her daughter and a mother in law expects to accommodate with gender inequality from her daughter in law. Hence the gender inequality is being nourished by the roots of culture and traditions in new India also. The only remedy to overcome from this problem is that the combined efforts must be taken by men and women both. There must be inculcation of the content promoting gender equality in the pattern of upbringing of male and female child both within the family. So that we could be able to control and change the behaviour pattern and attitude which promotes gender inequality in our society. It is essentially required for the entire family member to make cooperative efforts for making new generation realise that adoption of gender equality in practice is the only way to attain a harmonious and prosperous human society.

\section{Awareness about adverse effects of gender inequality}

It is also necessary to make the people aware about adverse effects of the practices of gender inequality like female foeticide, illiteracy and low level of education among women, dowry, domestic violence, negligence of women in decision making, economic inequality and harassment of women. Apart from this, woman represents the $50 \%$ population out of whole and if there will be imbalance between the ratio of male female, the after effects will be countless .Because the process of procreation and development in a civil society requires equality between men and women. The problem of female foeticide can adversely affect the whole society by creating imbalance between the ratio of men and women .Similarly illiteracy and low level of education among women can transfer the tendency of less preference of women's education to the next generation because in form of a mother women play pivot role in the family. The problems of women can never be removed without the participation. 
Women are the ultimate sufferer of their problems and their problems will be ultimately solved by the efforts made by them itself, which are based on their experience. Because it is a well-known truth that only sufferer could feel the intensity of the pain. Therefore the awareness about adverse effects of gender inequality must be created among men and women both to sensitize the generation. The young generation must be promoted to actively participate and promote the practices related to gender equality.

\section{Educational Advancement}

Strategies for advancement of women to attain higher literacy rate, formal education and greater employment opportunity. In education it needs to reduce primary and secondary dropout of female child. In post literacy, the basic literacy skills at speaking, reading, and writing and problem solving shall be imparted. Women learners should educate their children which further enhanced social advancement. In governance all rights and all legal measures should be available for women's protection and support. Human rights education, to know about how to take control of over adverse circumstance, help to achieve their own goals, helping themselves, enhancing their quality of life and motivating for lobbying or advocacy are also enablers for their advancement. Collaborators such as NGO, INGOs, and NPOs, SHGs, and CBOs, policy makers, local leaders, information disseminators, health care providers, teachers and family members should be motivated for the social advancement of women. Educational curriculum must include the contents related to positive effects

of gender equality. The teaching learning process must also include the gender sensitive practices to encourage gender equality among students in its real sense.

\section{Conclusion}

On the basis of above mentioned description it may be concluded that despite being socially, economically and technologically advanced, Indian society is still orthodox while dealing with matters of women .No matter in new India the education level, employment level, self- dependency has increased but on other hand dowry death, female foeticide, honour killing, women harassment at work place, domestic violence, acid attacks, rape and low level of political participation reflects that the women in India is still passing through the phase of gender discrimination. Hence we can say that the gender aspect of new India is not satisfactory and favourable and efficient efforts are required to be made in its real sense. For the given purpose it is essentially required to handle the problems of women in coordination with their circumstances with a democratic perspective. Regular monitoring and research work 
related to the operations and progress of activities promoting gender equality must be conducted with regular intervals.

The process of implementation and administration of the schemes promoting gender equality must have sensitive attitude towards the future prospects of the issue. It should be sensitively correlated with each and every members who are directly or indirectly associated in the process along with the stakeholders because the issue of gender equality is more concerned with humanity and protection of human rights. It is above of socio - cultural, economic, and political and other manmade boundaries which are conditioned with practices of gender discrimination from a longer period of time in India. Hence primarily the mental preparedness along with a sensitive attitude is primarily required to initiate for the issue. Each and every individual at all levels must be sensitise to actively participate in the process of awareness generation and initiation for behavioural change to control gender discrimination. Because people's participation is the most effective tool to eradicate any problem from roots.

\section{References}

1. Abrevaya, J. (2009): \Are There Missing Girls in the United States? Evidence from BirthData," American Economic Journal: Applied Economics, 1 \{34.

2. Gupta GR. Gender, sexuality, and HIV/AIDS: the what, the why, and the how. Can HIV AIDS Policy Law Rev 2000;5(4):86-93)

3. Adukia, A. (2014): \Sanitation and Education,"Working paper, University of Chicago.

4. Albanesi, S. and C. Olivetti (2009): \Gender Roles and Medical Progress," Working Paper 14873, National Bureau of Economic Research.

5. Alesina, A., P. Giuliano, and N. Nunn (2013): \On the Origins of Gender Roles: Women and the Plough," Quarterly Journal of Economics, 128, $469\{530$.

6. Almond, D. and L. Edlund (2008): ISon-Biased Sex Ratios in the 2000 United States Census," Proceedings of the National Academy of Sciences, 105, $5681\{5682$.

7. Anderson, S. (2003): \Why Dowries Payments Declined with Modernization in Europe but Are Rising in India," Journal of Political Economy, 111, 269 \{310.

8. ||| (2007): \The Economics of Dowry and Brideprice," Journal of Economic Perspectives, 21, $151\{174$. 
Gender and New India

Dr. Geetabjali Srivastava

9. Anderson, S. and C. Bidner (2014): \Property Rights over Marital Transfers," Mimeo, Simon Fraser University.

10. Anderson, S. and G. Genicot (2014): \Suicide and Property Rights in India," Working Paper 19978, National Bureau of Economic Research.

11. Anderson, S. and D. Ray (2010): \Missing Women: Age and Disease," Review of Economic Studies, 77, $1262\{1300$.

12. Anukriti, S. (2013): \The Fertility-Sex Ratio Trade-o: Unintended Consequences United Nations Development Program's Human Development Report 2013.

13. "India Dishonoured: Behind a Nation's War on Women", By Sunny Hundal, Guardian Books.

14. Chapters in Books: [3] High Level Expert Group (HLEG) on Universal Health Coverage (UHC), October 2010.Chapter 9 , Gender and Health, Universal Health Coverage (UHC) Initiative Of India. 